\title{
APRESENTACÃO
}

\section{Repensando objetos, arte e cultura material}

Com o declínio do interesse pelos amplos esquemas evolutivos e com um aumento das análises intensivas de sociedades específicas, o estudo da cultura material foi bastante abandonado em prol de um estudo da organização social, da mitologia e do ritual. Entretanto, a cultura material é uma parte importante da vida das pessoas. O que elas fazem, decoram e usam são parte integrante de sua cultura. Ignorar essas coisas é um erro tão grande quanto concentrar-se somente nelas. (Seeger, 1980, p. 41).

Os estudos antropológicos sobre objetos, aquilo que se convencionou denominar de cultura material, estão presentes desde os inícios mais remotos da disciplina. Certamente, essa denominação, cunhada nas origens acadêmicas da antropologia, vem passando por uma série de reformulações, respaldadas por posições teóricas e materiais etnográficos dos mais diferentes pontos geográficos. Minha pretensão aqui, nesta apresentação de uma farta discussão sobre o tema, representada pelo enfoque singular de cada um dos autores e autoras dos artigos ora publicados, é a de refletir sobre algumas dessas possibilidades e de trazer à tona a multiplicidade rica, densa e - por que não dizê-lo? - tensa dessas diferentes abordagens.

A antropologia, portanto, desde suas origens como disciplina acadêmica há pouco mais de cem anos, teve como pauta de seus estudos as manifestações artísticas e materiais dos diversos grupos com os quais entrou em contato. Os sistemas de objetos e de grafismos, os padrões arquitetônicos, as indumentárias e os adornos, sempre despertaram a atenção de uma série de profissionais da antropologia, na busca de suas relações com a cultura e a organização social específica de cada povo, de cada grupo investigado. Os primeiros momentos dessa aproximação do "mundo europeu" com os diversos coletivos foram marcados por posições colonialistas, na qual a busca e a interpretação de troféus materiais estiveram baseadas em princípios evolucionistas que objetivavam encaixar a produção material desses povos nos critérios etapistas da construção da explicação das diferenças. Igualmente, houve momentos em 
que os elementos estéticos ${ }^{1}$ de tais manifestações foram considerados fundamentais para a sua descrição e análise. Além dessas orientações, os estudos antropológicos sobre arte também sublinharam e continuam apontando questões ligadas à forma, à identidade, às relações sociais e aos discursos engendrados pelos objetos. Momentos mais recentes enfatizaram estas manifestações como expressão e materialização de importantes significados socioculturais desses coletivos, relativizando seu aspecto estético, principalmente aquele vinculado à visão de arte ocidental. Além disso, muitos outros trabalhos antropológicos têm lançado seus olhares sobre a inclusão da arte indígena, étnica ou tradicional nos circuitos artísticos e comerciais ocidentais, refletindo sobre as apropriações simbólicas, as permanências e as descontinuidades das suas lógicas nesses contextos de transformação.

A relação entre objetos e mercadorias, e as abordagens que enfatizam seus usos como marcadores e constituintes de um processo cultural que se constrói articulando muitos atores e construindo e consolidando sentidos, apresenta uma importante tradição de estudos na antropologia recente, especialmente aqueles que analisam o protagonismo dos consumidores a partir da aquisição de bens materiais.

Já a arte e a cultura material nos coletivos indígenas das terras baixas da América do Sul têm sido trabalhadas ultimamente desde as lógicas nativas, com a tendência de refutar a noção de estética como categoria transcultural, utilizando-se das categorias êmicas presentes nessa arte e em alguns desses objetos, singularmente concebidos como presentificações de relações estabelecidas com alteridades extra-humanas e suas potências, especialmente divindades e demais habitantes do cosmos (animais, plantas, minerais, etc.), dotados de atributos humanos, ponto de vista, subjetividade e intencionalidade. Nesse sentido, tais "objetos" são sujeitos, possuem agência e não são meras representações de protótipos: são eles próprios. Essa orientação não pretende deslegitimar as análises que enfatizam as manifestações artísticas e os sistemas de objetos como sistemas de representações, indicadores de processos identitários, de afirmação de sujeitos de direitos, de discursos variados e de importantes mensagens culturais neles contidos.

\footnotetext{
1 A partir de referenciais teóricos e de categorias de pensamento "ocidentais", ou, melhor dizendo, eurocentrados do que seria estética, sem levar em consideração as diversificadas e singulares categorias nativas.
} 
Os processos de patrimonialização, cuja intensificação nos dias atuais é notória, têm proporcionado um importante filão para estudos sobre cultura material, seja na sua relação com discursos relacionados a identidades, projetos políticos e subjetividades, seja na sua articulação com processos de revitalização de bens culturais e de preservação de memórias coletivas, seja na imbricação das noções de "bens materiais" e "bens intangíveis", seja na possibilidade de observar o entrelaçamento entre passado, presente e futuro, ou, ainda, na aproximação de duas categorias concebidas como antagônicas no pensamento "ocidental": as de patrimônio cultural e de patrimônio natural.

No âmbito dessa rica e complexa rede de abordagens e enfoques que se entrecruzam e que apenas esboçamos simplificadamente acima, desenha-se uma série de possibilidades analíticas da cultura material, refletidas nos artigos selecionados para este número de Horizontes Antropológicos.

O primeiro deles, "Desfetichizar para producir valor, refetichizar para producir el colectivo: Cultura material em uma cooperativa de 'cartoneros' del Gran Buenos Aires", de Sebastián Carenzo, da Universidad de Buenos Aires, aborda a questão do lixo e dos resíduos como mercadorias, etnografando os circuitos mercantis do trabalho de papeleiros a partir do enfoque da cultura material. $\mathrm{O}$ autor reflete sobre os diferentes regimes de valor, econômico e cultural, que esses objetos descartados adquirem nesses circuitos que articulam e mesclam uma diversidade de coisas, pessoas e coletivos, reconfigurando todos os três.

Renata de Castro Menezes, do Museu Nacional/Universidade Federal do Rio de Janeiro, em seu artigo sobre "A imagem sagrada na era da reprodutibilidade técnica: sobre santinhos", nos remete ao campo da materialidade da devoção e do culto aos santos, refletindo sobre as formas de interação textoimagem, ambos presentes nesses pequenos "retângulos de papel".

Em "La religión como cultura material. Socio-génesis de los circuitos editoriales en el mundo católico y evangélico", Joaquín Algranti, da Universidad de Buenos Aires, focaliza o vínculo que se estabelece entre religião e economia, analisando esses espaços de produção de bens culturais e de seu consumo, além de recuperar a dimensão de protagonismo dos atores neles envolvidos como produtores de significados a partir de bens materiais.

Baseado em sua etnografia com coletivos guarani, Fabio Mura, da Universidade Federal da Paraíba, no seu artigo intitulado "De sujeitos e objetos: um ensaio crítico de antropologia da técnica e da tecnologia", enfatiza 
a possibilidade de uma análise que supere a dicotomia Homem/Natureza, sociocultural/material, abordando "os elementos que constituem o cosmo como estando, segundo as circunstâncias, na posição de sujeitos de ação ou de objetos da ação".

Roberta Sampaio Guimarães, pesquisadora no Núcleo de Antropologia dos Objetos da Universidade Federal do Rio de Janeiro, em seu artigo de título "Entre vulgarizações e singularizações: notas sobre a vida social dos balaios", propõe-nos acompanhá-la na sua instigante etnografia sobre o percurso de alguns deles, ritualmente utilizados por praticantes do candomblé no Rio de Janeiro, traçando a biografia cultural desses objetos.

Em "Da invenção da tradição (ou de como os patrimônios nos inventam). Notas sobre a patrimonialização do pastoreio na Espanha", Luciana Braga Silveira, da Universidade Federal de Lavras, e Mercedes Pardo Buendía, da Universidad Carlos III de Madrid, fazem uma interessante discussão sobre o uso da cultura material como discurso, especialmente refletindo como se dá a agência dos patrimônios em relação aos atores sociais, suas subjetividades, identidades culturais e afirmação de seus direitos.

Cristian Jobi Salaini, da Escola Superior de Propaganda e Marketing, e Lucas Graeff, do Centro Universitário La Salle, no artigo "A respeito da materialidade do patrimônio imaterial: o caso INRC Porongos", trazem à tona a relação entre patrimonialização, disputas sobre a definição de bens culturais e configurações de identidades em terras gaúchas, analisando o contexto de um programa nacional de inventário de referências culturais e ressaltando e problematizando a relação entre "imaterialidade" e "materialidade" nos processos de patrimonialização.

Finalizando a secção de artigos, Hilaine Yaccoub, doutoranda na Universidade Federal Fluminense, aborda questões de consumo doméstico em “A chamada 'nova classe média'. Cultura material, inclusão e distinção social", a partir de sua etnografia em um bairro popular na região metropolitana do Rio de Janeiro, cujos moradores, por meio do consumo, almejam inclusão em outro estrato social, as camadas médias urbanas.

A secção Espaço Aberto apresenta duas entrevistas. A primeira, "Cultura e gastro-anomia: psicopatologia da alimentação cotidiana", traz ao nosso convívio, através das mãos de Miriam Goldenberg, o sociólogo Claude Fischler, Diretor de Pesquisas do Centre National de la Recherche Scientifique (CNRS) e codiretor do Centro Edgar Morin, associado à École des Hautes Études em 
Sciences Sociales. A segunda, "Uma trajetória antropológica", realizada por Pedro Jaime e Ari Lima, nos convida a dialogar com Didier Fassin, antropólogo e sociólogo francês, docente da École des Hautes Études en Sciences Sociales, onde fundou e coordena o IRIS (Institut de Recherche Interdisciplinaire sur les Enjeux Sociaux).

Nossa ilustração de capa, de autoria de Carla Luzzatto, traz uma composição de variados motivos relacionados à materialidade da cultura, procurando expressar e presentificar a intensa e multivocal rede de sentidos, processos, temporalidades, interações, discursos e análises que seus estudos engendram e desvelam.

Sergio Baptista da Silva

\section{Referência}

SEEGER, A. Os indios e nós: estudos sobre sociedades tribais brasileiras. Rio de Janeiro: Campus, 1980. 